\title{
Early Attention: A Study of the Underlying Mechanisms
}

Paul Craddock, Armelle Roux, Mikaël Molet and Claire Leconte-Lambert

\section{Q OpenEdition \\ 1 Journals}

Electronic version

URL: http://journals.openedition.org/cpl/467

DOI: $10.4000 / \mathrm{cpl} .467$

ISSN: $1379-6100$

Publisher

Centre PsyCLÉ

\section{Electronic reference}

Paul Craddock, Armelle Roux, Mikaël Molet and Claire Leconte-Lambert, «Early Attention: A Study of the Underlying Mechanisms », Current psychology letters [Online], 17, Vol. 3, 2005 | 2005, Online since 15 December 2005, connection on 11 September 2020. URL : http://journals.openedition.org/cpl/467 ; DOI : https://doi.org/10.4000/cpl.467

This text was automatically generated on 11 September 2020 .

(C) All rights reserved 


\title{
Early Attention: A Study of the Underlying Mechanisms
}

\author{
Paul Craddock, Armelle Roux, Mikaël Molet and Claire Leconte-Lambert
} 2000). Such an interpretation puts all the emphasis on the novelty factor to account for the orienting response (OR). In fact, most authors acknowledge the importance of other factors to account for the amplitude of the OR but they need to refer to novelty to interpret its activation.

7 This paper aims at suggesting a new conception of the orienting response that can be applied whatever the factor that enhanced it and which remains consistent with Sokolov's definition of the OR as a preparatory, information-catching mechanism, (Sokolov, 1990). However, we would like, first, to make a review of the different wellknown factors activating the subject's attention.

What does attract attention?Significance

8 The significance a stimulus bears can create an OR that will activate attention. If it is difficult to precisely determine what "significant" refers to, we can nevertheless consider with Maltzman (1987) that significance is acquired through learning, either because the subject has learnt that the stimulus is the signal of a mental or motor activity, or because it predicts the introduction of an already significant event. A 
stimulus can also be significant when it evokes a special interest in the subject's life (Wingard \& Maltzman, 1980). Cohen (1973) mentioned the importance of this factor in the four-month-old infant, stating that the attention-getting process is partly dependent on how interesting or reinforcing the pattern has been in the past. Some stimuli are probably significant from birth as a result of foetal learning. As Malcuit, Pomerleau and Lamarre (1988) have already pointed out, when De Casper and Spence (1986) observed that newborn babies pay attention to familiar stimulus heard in the mother's womb, it probably does not imply that he is trying to build up an inner representation of the stimulus.

Novelty

9 Paradoxically, enhancement of attention can also reflect a lack of learning. The novelty factor is often referred to as an activator of attention. Much research, over these last thirty years has shown the early ability to detect a variation, even if it is slight, in a familiar pattern. The interpretation adopted is the neuronal model introduced by Sokolov in 1963, according to which an inner representation of the stimulus progressively builds up throughout the trials. The more complete the inner representation, the less intense the reaction to the stimulus will be. At this stage, a modification in the familiar pattern will enhance attention as there is a mismatch between the representation and what is actually presented in the sensorial field. It is, hence, learning of the stimulus characteristics that allow a decrease in the orienting response amplitude, when the event is not significant. In the case where the stimulus becomes significant, for example because the subject starts learning that it predicts the introduction of an event already significant for him, the first mechanism sensitive to the significant nature of the stimulus would compensate for the effect of habituation. Attention would then remain activated at every introduction of the significant pattern. Predictability

10 Another factor that should be taken into account in the study of what produces the OR is how surprising is the introduction of a stimulus. In other words: is the stimulus new in the context? The more an event is expected, the less it will activate attention. This factor, to a certain extent, includes the previous one: a novel stimulus cannot be predicted. Clifton (1974) as well as Blass, Granshow and Steiner (1984), seems to have evidenced the ability of newborn babies to learn the association of two events. Cifton noticed a clear heart rate deceleration when the unconditioned stimulus (US) was omitted after the conditioned stimulus (CS), hence revealing an activation of attention to the omission of an expected event. As for Blass et al. (1984), they showed that most infants cried when the sucrose solution (US) was not delivered after the CS (forehead stroking) during extinction. Obviously, these observations are to be related to what Sokolov (1990) called the " missing stimulus effect".

11 It seems, then, that when what happens differs from what was expected to happen, even the newborn baby reacts with activation of attention. Intensity

12 Barry (1982) suggested, in his model of the adult's orienting response, that the intensity factor interacts with the novelty factor to produce the orienting response. Cohen (1973) included the intensity factor in his conception of the attention-getting process, involving stimulus dimensions such as brightness, size and movement in the attraction of attention. We would like to stress however that attention can be activated without 
the intervention of the intensity factor, as Clifton (1974) showed when she omitted to introduced a predicted event: the babies reacted to the absence of the stimulus.

Rescorla introduced a model in 1972 involving the two latter factors and allowing a quite satisfactory prediction of how intense the subject's orienting response should be to a non -significant pattern. Unfortunately this model has seldom been mentioned in the field of infants' attention.

To put it in simple words, according to that model, attention is more readily paid to a stimulus when the event that happened just before did not allow the subject to predict its introduction in the sensorial field as indicated in Rescorla's formula:

$15 \delta \mathrm{V}=\alpha \beta(\lambda-\mathrm{V})$

16 The amplitude of attention ( $\delta \mathrm{V})$ to a repeatedly introduced pattern (P2) progressively decreases as the associative strength $(\mathrm{V})$ between this pattern and what preceded (P1) increases. The model also emphasizes the role of both the pattern's intensity $(\beta)$ and the intensity of $\mathrm{P} 1(\alpha) . \lambda$ represents the absolute maximal associative strength between P1 and P2.

17 Hence, when P2 (either familiar or novel) comes for the first time after P1, the associative strength between the two patterns $(\mathrm{V})$ tends towards zero and $\delta \mathrm{V}$ will be maximal. If the two patterns are repeatedly introduced together, $\mathrm{V}$ will increase throughout the trials and $\delta \mathrm{V}$ will decrease to eventually reach a very low amplitude when $\mathrm{V}$ tends towards $\lambda$.

$18 \delta \mathrm{V}$ originally designated the amount of learning of the associative strength by the subject at a specific trial, but as the amount of learning depends on the level of attention granted to the situation, it is a relevant estimation of the amplitude of the OR. The evolution of $\delta V$ over the trials follows the typical curve of habituation, as $V_{n}=V_{n-1}$ $+\delta \mathrm{V}_{\mathrm{n}}$

19 One of the interests of applying such a model to the baby would be to predict that the subject would pay attention, not only to novel stimulus, but also to familiar target which occurrence is surprising in the context and to predict the missing stimulus effect.

What does maintain attention?

20 A complete model of attraction of attention should also account for the on going sensorial analysers' activity. We will limit our study to non-significant patterns as it is probably very difficult to find any satisfactory interpretation of why a subject will stop staring at an attractive significant stimulus.

21 Cohen (1973) proposed a model that can account for both duration of fixation at each trial and habituation of visual fixation over the trials. He suggested that a representation of the visual target builds up in the babies' short-term memory at each trial, to which the physical stimulus is compared. The subject fixates until there is a match between the external pattern and its short-term representation. This first part of the model accounts for cessation of fixation at a given trial.

22 As for interpreting habituation, the idea is that, progressively, throughout the trials, stimulus components are stored in the long-term memory until completion of the longterm memory representation. At that stage, the stimulus will no longer be attractive. Hence, over the trials, the time spent staring at the target will decrease because only 
the missing elements (those not yet stored in long term memory) will have to be memorised. The fewer elements to store, the shorter fixation will be.

One of the limits of relating fixation to the completion of an inner model is that it cannot account for the baby's interest for a familiar non-significant pattern. Indeed, Kaplan and Werner (1987) evidenced the fact that four-month-old infants, retested with a previously familiarized target shortly after exposure to a novel complex target exhibit a recovery in fixation of the familiar pattern. Any reference to Cohen's model would imply that the subject has forgotten the first pattern's characteristics. Bashinski, Werner and Rudy (1985) also obtained an increase in infant's fixation time between the first and the second introduction of a fairly complex visual target. According to these authors, the first introduction of the pattern has sensitized the fixation to every pattern introduced in the visual field within a fairly short period of time, that is to say, before the effect of sensitization has waned. The author's interpretation draws upon the two-process theory introduced by Groves and Thompson (1970), in which the strength of the behavioural response elicited by repeated stimulations is assumed to result from two inferred, independent processes: habituation and sensitization. Habituation is the process that mediates response decrement whereas sensitization is responsible for temporary behavioural response increment, the effect of sensitization decaying spontaneously over time. Thompson, Groves, Teyler and Roemer (1973) described sensitization as an incremental process in a state of excitation or tendency to respond of the organism, following, not only the introduction of a strong (intense), but also following an extra (unexpected) or different (novel) stimulus. Therefore, the same characteristics that activate the subject's attention increase the organism general responsivity to the environment through sensitization. As it has already been stated, the organism will not remain permanently in that state of greater responsiveness because of the spontaneous decay of the sensitization's effects.

A unique interpretation of what attracts and what maintains attention

We would like to suggest that the activation of attention through the orienting response is, in fact, sensitizing of attentional responses. As a consequence, the time spent attending to a non-significant stimulus can be determined by how important the sensitization has been. Indeed, the subject will tend to pay attention to the pattern until the effect of sensitization has waned spontaneously. While these effects spontaneously decay, the analysers' response becomes less and less intense and the fixation response becomes less and less probable. This interpretation seems to emphasize Sokolov's conception of the OR as a mechanism that facilitates the reception of stimuli, increasing the sensitivity of analysers and facilitating learning (Sokolov, 1963).

26 Applied to babies' attention, it would imply that young subjects attend to a target, not to complete its inner model in memory as Cohen proposed, but because the mechanism that increases attention has automatically been activated through the orienting response. Until the increased activation has waned, the subject's responsiveness to the environment remains more important. As a consequence, the factor that determines the interruption of visual fixation at each trial is not the match between what is seen and what is stored in the short-term memory, but the spontaneous waning of the orienting response's effect, whether the OR was due to novelty, intensity or the unexpected nature of the pattern. 
Moreover, habituation of fixation is no longer described as reflecting the progressive completion of a representation in long-term memory but as being the result of habituation of the OR which is sensitization of attentional responses. The weaker the OR, the shorter fixation time will be.

One may object the fact that the main characteristic of the OR is that it habituates, whereas sensitization effects decay spontaneously over time, independent of the number of exposures. However, it seems to us that nothing in the two-process model presented by Groves and Thompson (1970) contradicts the idea that the activation of the mechanism that sensitizes does habituate as well as the organism's response. It is the increased sensitivity, resulting from the intervention of this mechanism that decays spontaneously.

Hence, the orienting response habituates because the target becomes more and more predictable. The OR being weaker and weaker, the decay of its effects on the subject's responsiveness to the target takes less and less time, producing shorter fixation times.

Kaplan and Werner's results of 1987 can consistently be analysed in the light of this new interpretation. The familiar target re-introduced has become less predictable in the context following the presentation of an extra novel pattern. We also suggest that it has become slightly significant: As the baby could not accurately predict the nature of the visual target, its introduction bears some interest. The OR accompanying the familiar pattern sensitizes attention to the target.

Predictions consistent with an interpretation based on sensitization

31 As a final comment on this hypothetical mechanism that underlies attention, we would like to predict how babies should react in two different specific situations if a little credibility can be granted to what we proposed. the visual stimulus is omitted after the sound, we expect a recovery of fixation to the screen even if there is nothing to see on it. The unexpected event in that case would be the absence of the target. The intensity of fixation response should decrease as sensitization decays. Any reference to a model suggesting that fixation is determined by the necessity of creating or completing an inner representation would imply that babies try to make a representation of an empty screen.

Unfortunately, the only experiment we know of, showing a clear "interest" for " empty space", has been performed with rats. Indeed, Xavier, Porto Saito and Stein (1991) observed a progressive decrease in the time spent paying attention to an object regularly located at the same place in a familiar alleyway. However, after this habituation period, if the target was completely removed from the alleyway, the rats attended to the place where "it should have been" although there was nothing to see. In front of such results, it appears difficult to refer to any interpretation in terms of completion of an inner model. Even if we are aware of the fact that the mechanism underlying attention in the rat is probably quite different from the one regulating attention in the infant, we believe that similar results would be observed with young human subjects using an adapted procedure.

Moreover, the authors observed that the animal re-started exploring the familiar object when it was moved to a different place of the alleyway. One could argue that, in that case, the stimulus was indeed novel because of its presence in a different context. Such an argument suggests that the rat is "trying " to memorise not only the physical 
characteristics of a target but also the link between this target and the context in which it is found. If indeed the subjects fixate in order to memorise a link between events, they should not stare at an empty screen in the experiment we proposed as a challenge to our theory. Yet, we predict they will fixate although there is neither any target nor any link between events perceptible in the environment.

In the following paragraph, we propose another experimental procedure that would be a challenge to any interpretation of fixation in terms of memorising the stimulus' characteristics or the link between the stimulus and its environment.

Maintenance of attention is predicted not only for novel stimulus for which a representation has to be built up, but also for familiar targets introduced after an alteration in a regular sequence of trials. Let us imagine an experimental procedure in which a unique target is presented several times after an inter-stimulus interval of, say, ten seconds. When habituation has taken place, the light is switched off for about two seconds, just before re-introducing the familiar target. Note that the target appears exactly in the same context as previously. The unexpected event occurs just before but is no longer present when the target is introduced. Anybody would predict that the baby will not stare at the familiar target when presented after a peculiar event if, as Cohen suggested, an inner representation of the physical characteristics was to be completed. Yet, we predict that the babies will fixate the familiar target in such conditions. Indeed, from Rescorla's model, we anticipate that the unexpected event (the switching off of the light) will enhance an OR that sensitizes the organism's responses. According to Groves and Thompson (1970), the effects of sensitization will decay over time. During that period of decay, the subjects' attentional responses will remain increased until the process of decay is completed. If during that same period we introduce a familiar target, we expect that a greater level of attention will be granted to it than the asymptotical level typical of habituation.

Hence, our view of early attention is that it results from an automatic process (the OR) that increases the organism's responsiveness to the environment. Attentional responses will also be sensitized creating fixation whether there is something to see or not and whether what is present is a novel or a familiar target. Cessation of fixation is not seen as determined by the level of completion of an inner representation but rather by the spontaneous decay of the orienting response's effects.

The fact of fixating a familiar target in a new context or after a new event should allow the subject to be more responsive if, in these new conditions, the stimulus is to be followed by something interesting or important. If it is so, the target itself will start getting significant, if not, habituation should take place.

Learning which events are significant and which are not, probably is the main task babies have to perform in order to adapt themselves to the complex environment in which they have to live. 


\section{BIBLIOGRAPHY}

BARRY, R.J. (1982). Novelty and significance effects in the fractionation of phasic OR measures: a synthesis with traditional OR theory. Psychophysiology, 19, 28-35.

BASHINSKI, H.S., WERNER, J.S., \& RUDY, J.W. (1985). Determinants of infant visual fixation: evidence for a two-process theory. Journal of Experimental Child Psychology, 39: 580-598.

BLASS, E., GRANCHROW, J. \& STEINER, J. (1984). Classical conditioning in newborn humans 2-48 hours of age. Infant Behavior and Development, 7, 223-235.

CLIFTON, R.K. (1974). Heart rate conditioning in the newborn infant. Journal of Experimental Child Psychology, 18, 9-21.

COHEN, L.B. (1973). A two process model of infant visual attention. Merrill-Palmer Quaterly, 19, 157-180.

DE CASPER, A.J., \& SPENCE, M. (1986). Prenatal maternal speech influences newborns' perception of speech sounds. Infant Behavior and Development, $\underline{9}, 133-150$.

GROVES, P.M., \& THOMPSON, R.F. (1970). Habituation: a dual-process theory. Psychological Review, 77, 419-450.

KAPLAN, P.S., \& WERNER, J.S. (1987). Sensitization and dishabituation of infant visual fixation. Infant Behavior and Development, 10, 183-197.

MALCUIT, G., POMERLEAU, A., \& LAMARRE, G. (1988). Habituation, visual fixation and cognitive activity in infants : a critical analysis and attempt at a new formulation. Cahiers de Psychologie Cognitive 2 8, 415-440.

MALTZMAN, I., VINCENT, C., \& WOLFF, C. (1982). Verbal conditioning, task instructions, and inhibition of the GSR measure of the orienting reflex. Physiological Psychology, 10, 221-228.

MARESCHAL, D. \& FRENCH, R. (2000). Mechanisms of categorization in Infancy. Infancy, 1, 59-76. RESCORLA, R.A. (1972). Information variables in pavlovian conditioning. In G. BOWER (Ed), The Psychology of learning and motivation: vol. 6. New York : Academic Press.

SOKOLOV, E.N. (1963). Perception and the conditioned reflex. New York: Mc Millan.

SOKOLOV, E.N. (1990). The orienting response, and future directions of its development. The Pavlovian Journal of Biological Science, 25, 142-150.

THOMPSON, R.F., GROVES, P.M., TEYLER, T.J., \& ROEMER, R.A. (1973). A dual-process theory of habituation : theory and behavior. In H. PEEKE \& M.HERZ (Eds), Habituation : behavioral studies : vol. 1. New York : Academic Press.

WINGARD, J., \& MALTZMAN, I. (1980). Interest as a predeterminer of the GSR index of the orienting response. Acta Psychologica, 46, 153- 160.

XAVIER, G.F., PORTO SAITO, M.I., \& STEIN, C. (1991). Habituation of exporatory activity to new stimuli, to the absence of a previously presented stimulus and to new contexts in rats. The Quaterly Journal of Experimental Psychology, 43B, 157-175. 


\section{ABSTRACTS}

The first part of this paper aims at discussing on the impact of different factors in early activation of attention. The orienting response (O.R.), presented as a mechanism that activates attention results, not only from the novelty factor but also from the stimulus significance and intensity, and from its unexpected nature. The second part of the paper introduces an interpretation of what maintains attention refering to a physiological process called sensitization. This interpretation is proposed as an alternative to Cohen'model, (1973).

La première partie de cet article a pour but de présenter l'impact des différents facteurs de l'activation précoce de l'attention. La réaction d'orientation (R.O.), décrite comme un mécanisme qui active l'attention, est présentée comme résultant, non seulement de la nouveauté du stimulus mais aussi de sa significativité et de son intensité ainsi que de son caractère inattendu. La seconde partie de l'article introduit une interprétation de ce qui maintient l'attention, en faisant référence au processus physiologique de sensibilisation. Cette interprétation est proposée comme une alternative au modèle de Cohen (1973).

\section{INDEX}

Keywords: Attention, Habituation, infants, Orienting response, Sensitization

\section{AUTHORS}

\section{PAUL CRADDOCK}

Department of Psychology

University of Lille 3 B.P. 60149.

59653 Villeneuve d'Ascq Cedex, France

paul.craddock@univ-lille3.fr

ARMELLE ROUX

Department of Psychology, University of Lille, France

\section{MIKAËL MOLET}

Department of Psychology, University of Lille, France

\section{CLAIRE LECONTE-LAMBERT}

Department of Psychology, University of Lille, France 